JALADRI (Vol. 7.1) (2020)

Jurnal Pendidikan Bahasa dan Sastra Daerah

http://jurnal.upmk.ac.id/index.php/jaladri/

\title{
NASKAH DRAMA "WANCI" \\ UNTUK BAHAN PEMBELAJARAN APRESIASI DRAMA DI SMA KELAS XII
}

\section{Arifa Rachmani}

arifarachmani16@gmail.com

MGMP Bahasa Sunda Tasikmalaya

\section{Info Artikel}

Sejarah Artikel:

Diterima 10 Januari 2021

Disetujui 10 April 2021

Dipublikasikan 25 April 2021

Kata Kunci:

naskah

drama;

struktural;

semiotik;

bahan ajar.

\begin{abstract}
Abstrak
Naskah drama "Wanci" merupakan naskah drama yang penuh makna sehingga perlu dianalisis secara struktural dan semiotik, yang kemudian dapat dijadikan alternatif bahan pengajaran. Adapun tujuan penelitian ini adalah untuk mendeskripsikan: 1) struktur naskah drama "Wanci" karya Ayi G. Sasmita; 2) unsur semiotik; 3) penerapan hasil analisis struktural dan semiotik sebagai alternatif bahan ajar apresiasi drama di SMA kelas XII. Metode yang digunakan yaitu metode deskriptif analisis yang secara langsung mendeskripsikan struktur cerita dan unsur semiotik yang terdapat pada naskah drama tersebut. Teknik mengumpulkan data yaitu telaah pustaka dengan cara menilai, mendalami, menelaah dan mengindentifikasi sumber berupa naskah drama. Hasil dari penelitian ini meliputi tema tentang persoalan moral dan religi, tokoh terbagi menjadi dua, tokoh utama dan tambahan, alurnya maju, latarnya yaitu tempat, waktu dan suasana, amanatnya adalah harus saling mengingatkan dan sabar dalam menjalani kehidupan serta tidak lupa melakukan kebaikan agar mendapat berkah di akhirat kelak. Naskah drama ini dibangun oleh prolog, dialog, adegan, aside wawacang dan epilog. Berdasarkan hasil analisis semiotik, bisa diketaui bahwa naskah drama "Wanci" karya Ayi G. Sasmita mempunyai ungkapan yang mengandung makna, terbuktu dengan adanya 11 ikon, 31 indeks dan 37 simbol. Hasil analisis struktural dan semiotik ini dapat digunakan sebagai alternatif bahan ajar aprésiasi drama di SMA kelas XII.
\end{abstract}




\section{Abstrack}

Key Words:

drama script;

structural;

semiotic; teaching

material.
The background of this research is curiousity of drama script"Wanci" by Ayi G. Sasmita related to the story and full of implied meaning. Therefore, this drama script need to researched by structurals and semiotics. The purpose of this study is to describe: 1) drama script structure which includes; 2) semiotic elements; 3) application of structural and semotic analysis result as materials of drama appreciation lessons at high school XII's grade. The methods that used in this research is descriptive analysis method. As for data collection techniques using library review by judging, deepen, examine and identify the source in the form of drama script. The results of this study are general theme in this drama script is moral and religious issues, the character is divided ito the main and additional characters, the plot is forward, the setting is setting of the place, time and atmosphere, the message is humans must remind one another and patiently live life and not forget to do good in order to get blessing in hereafter. This drama script is built by the prologue, dialogue, scene, round, wawacang, aside and epilogue. Based on the results $f$ the semiotic analysis, can be known that drama script "Wanci" by Ayi G. Sasmita has a meaningful expression, proven by the existence of 11 icons, 31 indexes and 37 symbols. The results of structural and semiotics analysis drama scriot "Wanci" by Ayi. Sasmita can be used for drama appreciation lessons at high school XII's grade. 


\section{PENDAHULUAN}

Sastra merupakan hasil kreativiats manusia yang mengandung unsur estetis dan unsur kehidupan (Mustaqim, dkk., 2019). Selain itu, karya sastra tentu merupakan hasil imajinasi manusia yang dituangkan dalam bentuk tulisan. Semi (2012: 1) menyebutkan bahwa adanya sastra disebabkan karena adanya dorongan dari diri manusia untuk menunjukkan jati diri, adanya minat pada masalah-masalah yang dihadapi dan adanya minat pada realita yang terjadi pada setiap jaman. Sesuai dengan pendapat tersebut, karya sastra dan kehidupan manusia saling berkaitan dan tidak bisa dipisahkan. Sastra bukan termasuk komunikasi praktis, tapi berupa komunikasi yang mengandung unsur seni dan unsur kreatif. Menurut Isnendes (2010: 10) yaitu karya sastra sebagai proses kreatif yang tiada lain ekspresi pengarang dalam menorehkan karyanya melalui medium bahasa, baik lisan maupun tulisan. Unsur keindahan dalam naskah drama merupakan imaji dari kehidupan manusia. Hal tersebut sesuai dengan pendapat Tambajong (dalam Darisman, 2015).

Salah satu bentuk karya sastra yaitu cerita drama, yang menyajikan cerita atau peran dalam bentuk dialog, diajukan untuk diperankan oleh aktor dalam pagelaran drama (Isnendes, 2010:75). Selain itu, drama juga merupakan karya sastra yang mengungkapkan cerita dengan media dialog-dialog tokoh (Koswara, 2010: 115). Pengarang naskah drama juga banyak mengadaptasi beberapa kejadian yang dialami oleh manusia sehari-hari (Asmaniah, 2015). Dengan demikian, drama merupakan salah satu karya sastra yang menggambarkan tingkah laku manusia yang mengandung konflik dalam bentuk dialog dan akting di depan penonton. Menurut Isnendes (2010: 75) drama dibagi dua, yaitu drama tradisional dan drama modern. Drama modern ada yang dinyanyikan atau semi modern dan diperankan biasa. Drama tradisional yaitu bentuk teater yang dihasilkan dari masyarakat etnik. Drama modern, bentuk teater yang berdasarkan tradisi tulis sebagai hasil budaya Indonesia setelah adanaya campuran dari budaya barat. Menurut Dewojati (2010: 1) drama diciptakan untuk menghibur dan memberi manfaat kepada pembaca (jika drama tersebut berupa tulisan atau naskah) dan untuk penonton (jika drama tersebut dipergelarkan). Sebagai sastra dalam bentuk tulisan, drama mempunyai kedudukan yang sama dengan prosa dan puisi, yaitu untuk diapresiasi. Menurut Endraswara
(2011: 144) drama adalah karya sastra yang indah karena memiliki unsur estetika dan artistik, oleh sebab itu perlu diapresiasi.

Drama bisa diapresiasi selain dengan membaca naskahnya juga sekaligus dapat menganalisis strukturnya. Bahkan kegiatan mengapresiasi ini dapat dikategorikan sebagai kegiatan literasi budaya sebagaimana dikatakan Suherman (2019). Berkaitan dengan hal tersebut, Abrams (dalam Koswara, 2013: 12) menyebutkan bahwa ada empat pendekatan menganalisis karya sastra, yaitu 1) kritik mimétik, yang mengacu berdasarkan pendapat bahwa karya sastra merupakan gambaran dari dunia kehidupan mausia, 2) kritik pragmatik, yaitu kritik yang disusun untuk mencapai tujuan yang pasti untuk pembacanya, 3) kritik éksprésif, yaitu kritik yang menegaskan telaahnya pada keterampilan pengarang dalam menuangkan gagasannya, 4) kritik objéktif, yaitu kritik sastra berdasarkan pada pendapat bahwa karya sastra merupakan karya yang mandiri, mempunyai dunianya sendiri. Menurut Hasanuddin (2009: 93-123) karya sastra bentuk drama mempunyai unsur-unsur yang sama dengan karya sastra yang lainnya seperti novel, roman atau cerita pendek, yaitu tema, tokoh, latar, alur dan amanat (unsur pembangun cerita drama).

Menurut Mukarovsky (dalam Faruk, 2015: 77) karya sastra merupakan fakta semiotik. Adapun semiotik adalah merupakan pengembangan dari pendekatan struktural. Semiotik bisa menemukan makna setiap unsur yang ada di dalam naskah drama. Secara etimologis, kata semiotik berasal dari bahasa Yunani "semeion" atau "semion" (tanda). Jadi, semiotik yaitu ilmu tanda. Tanda mempunyai arti yang luas. Seperti suara, rasa, bentuk, semua termasuk tanda (Isnendes, 2018: 97). Menurut Barthes (dalam Isnendes 2010: 57) semiotik meneliti segala sistem tanda, apapun substansi dan batasannya: gerak, suara, musik, atau asosiasi kompleks dari semuanya. Dari pengertian tersebut, dapat disimpulkan bahwa semiotik yaitu ilmu yang meneliti tentang tanda dan segala hal yang berkaitan dengan tanda dengan tujuannya untuk menemukan arti yang sebenarnya.

Selain itu, pengajaran drama di sekolah bisa menjadi media yang efektif untuk menumbuhkan nilai-nilai yang ada kaitannya dengan aspek kehidupan (Pratama, 2018). Oleh karena itu, hal tersebut menjadi dasar mengapa naskah ini dipilih sebagai salah satu usaha untuk mengembangkan budaya Sunda dan bahasanya, serta mengembangkan pengajaran bahasa Sunda dalam bidang pendidikan dengan menggunakan kriteria 
bahan ajar menurut Nasution (dalam Haerudin dan Kardana, 2013:77) yaitu 1) tujuan yang ingin dicapai; 2) dianggap memiliki nilai untuk kehidupan manusia; 3) dianggap memiliki nilai warisan dari jaman sebelumnya; 4) memiliki guna untuk menguasai ilmu lain; dan 5) sesuai dengan kebutuhan dan minat siswa.

Penelitian yang membahas naskah drama masih terbilang langka. Sesuai dengan pendapat Dwijayanto (2015) yang menyebutkan bahwa naskah drama masih kurang diapresiasi karena naskah drama di Indonesia belum didokumentasikan secara benar. Penelitian yang membahas tentang naskah drama di antaranya "Analisis Naskah Drama "Meredong" karya Rosyid E. Abby Saduran tina Naskah Drama "Ke" karya Yudhistira ANM Massardi" yang diteliti oleh Sanjani (2012); "Naskah Drama "Jeblog" karya Nazarudin Azhar (Tilikan Strukturalisme Genetik)" oleh Yosef M. Ibrahim (2014), "Analisis Semiotik Naskah Drama "Sadrah" karya Nazarudin Azhar" oleh Yokeu Darisman (2014), "Analisis Struktur jeung Psikologi Sastra Naskah Drama "Jam Hiji Dua puluh Salapan Menit" karya Ayi G. Sasmita" oleh Ryan Rubi Pasha, serta "Naskah Drama "Raja Wales" karya R. Hidayat Suryalaga pikeun Alternatif Bahan Pangajaran Apresiasi Drama di SMA kelas XI (Ulikan Struktural jeung Semiotik)" oleh Ferdina Husdianto.

Naskah drama "Wanci" karya Ayi G. Sasmita sejauh ini belum pernah diteliti secara struktural dan semiotik. Oleh karena itu, penelitian ini perlu dilaksanakan.

\section{METODE PENELITIAN}

Penelitian ini menggunakan pendekatan kualitatif deskriptif terhadap karya sastra. Menurut Semi (1990:24) penelitian kualitatif deskriptif yaitu data yang sistematis dalam bentuk kata-kata atau gambar-gambar, bukan dalam bentuk angka. Metode merupakan cara utama yang digunakan untuk mengumpulkan data penelitian dengan menggunakan teknik serta alatalat (Arikunto, 2013: 203). Penelitian tentang "Wanci" karya Ayi G. Sasmita ini merupakan penelitian kualitatif dengan menggunakan metode deskriptif.

Sumber data penelitian ini adalah naskah drama "Wanci" karya Ayi G. Sasmita. Naskah ini tidak secara resmi diterbitkan atau dibukukan, melainkan merupakan koleksi Teater Sunda Kiwari yang secara rutin mengadakan Festival Drama Basa Sunda, baik kategori siswa maupun kategori umum. Lahirnya karya Naskah drama "Wanci" ditulis untuk dipentaskan dalam Festival Drama Basa Sunda ketegori umum tahun 2017. Naskah drama ini terdiri atas 23 halaman dan ditulis tanggal 13 September 2017 di Subang oleh Ayi G. Sasmita.

Penelitian ini menggunakan teknik telaah pustaka. Telaah pustaka yaitu menelaah, mendalami, dan mengidentifikasi sumber yang berkaitan dengan objek penelitian. Teknik penelitian ini digunakan ketika mengumpulkan data untuk menganalisis data dan mencari sumber data lain yang mendukung untuk penelitian yaitu dengan cara membaca sumber data yang berkaitan dengan srukturalisme, semiotik dan bahan pengajaran. Desain penelitian yang digunakan dalam penelitian ini adalah: 1) persiapan, peneliti menentukan masalah, membaca buku dan menentukan instrumen; 2) mengumpulkan data, menggunakan teknik telaah pustaka; 3) mengolah data; dan 4) menyusun laporan/tulisan.

\section{HASIL DAN PEMBAHASAN}

Berdasarkan hasil penelitian tentang naskah drama "Wanci" karya Ayi G. Sasmita, didapatkan hasil analisis struktural, semiotik dan bahan pengajaran.

\section{Deskripsi Naskah Drama "Wanci"}

Naskah drama yang berjudul "Wanci" merupakan salahsatu karya Ayi G. Sasmita. Karya Ayi G. Sasmita bukan hanya menceritakan tentang kehidupan sehari-hari. Ada beberapa naskah drama yang termasuk ke dalam aliran surrealis yaitu naskah drama yang memiliki jalan cerita di luar akal manusia. Isi cerita naskah drama yang memiliki aliran surrealis tidak bisa dimengerti dengan sekali membaca, contohnya yaitu naskah drama "Jam Hiji Dua Puluh Salapan Menit" dan "Wanci" karya Ayi G. Sasmita.

Apabila dilihat dari isi cerita, naskah drama ini termasuk aliran naskah drama surrealis karena menggambarkan perjalanan manusia dengan cara yang berbeda. Setiap tokohnya hanya memiliki satu karakter atau sifat yang disesuaikan dengan nama tokoh itu sendiri. Beberapa ucapan yang diungkapkan oleh tokoh dan jalan ceritanya mengandung makna yang tersirat. Naskah drama ini juga secara tidak langsung menunjukkan nilai moral yang positif untuk kehidupan manusia.

\section{Ringkasan Naskah Drama "Wanci"}

Suatu hari di tempat yang tidak biasa, terdengar suara-suara aneh seperti suara orang 
menangis, suara wanita melahirkan dan suara bayi baru lahir. Tak lama kemudian, datanglah Ki Umbara denga rambut dan jenggot putihnya yang menjuntai panjang. Lalu Ki Umbara memberikan beberapa nasihat, bahwa alam dunia hanya sementara. Tidak lama kemudian, terdengar suara aneh lagi. Semakin lama semakin berpusat pada suara wanita yang melahirkan dan diikuti oleh suara bayi menangis. Terdengar suara adzan lalu suara komat. Entah dari mana datangnya, tiba-tiba masuk jabang bayi yang berloncatan.

Di tempat yang lain, ada si Utun. Utun telah melakukan perjalanan dari subuh melewati tempat-tempat yang aneh dan belum pernah tersentuh manusia. Si Utun menyebrang sungai yang airnya keruh, melewati hutan yang penuh dengan manusia berpakaian mewah dan kota yang bangunannya megah namun seluruh isinya hanyalah binatang-binatang. Lalu si Utun beristirahat di tempat itu sembari sedikit bernyanyi menghabiskan waktu. Karena kelelahan, Utun tertidur. Tak lama kemudian, datanglah Amar yang berjalan perlahan sembari membawa banyak barang. Ia membawa banyak karung yang berisi tambang yang terbelit. Lalu Amar duduk menyimpan barang-barangnya kemudian karung yang ia bawa dikeluarkan isinya. Terlihat rupa-rupa tambang, panjang dan besarnya berbeda-beda. Tanpa sengaja, Utun terbangun karena Amar yang tiba-tiba marah karena kesal tambangnya selalu terbelit. Lama kelamaan, Utun dan Amar malah mengobrol. Ternyata kedua orang tersebut sedang dalam perjalanan menuju tempat yang sama, yaitu gawir magrib. Tak lama, datanglah seorang perempuan muda bernama Princes yang berpakaian seksi sedang menelepon. Princes menelpon dengan nada genit. Lalu Princes menoleh pada Amar dan Utun karena kaget, ia menyangka hanya dirinya saja yang ada di tempat itu. Lama mengobrol, lalu semua Utun, Amar dan Princes melihat dua orang tua yang baru saja datang. Ki Umbara dan Ni Umbara berjalan sambil saling menuntun tak lupa membawa cempor sebagai penerangan. Kakek dan nenek tersebut saling membalas canda sambil saling mencubit, terlihat ekspresi bahagia sehingga mereka lupa jika ada orang di sekitar mereka. Seperti biasanya, Amar memarahi Ki Umbara dan Ni Umbara padahal Amar telah dinasihati orang-orang untuk menghormati orangtua. Ki Umbara tetap sabar, malah meneruskan candaannya pada Ni Umbara. Karena itulah, Princes malah cemburu melihat perlakuan Ki Umbara pada Ni Umbara.
Matahari telah tenggelam, di suatu tempat terdapat saung. Di tempat itu Ki Umbara sedang bersila di depan saung sambil menyisir jenggotnya yang putih menjuntai. Ni Umbara keluar dari dalam saung berjalan perlahan sambil melihat sekitarnya seolah ada sesuatu yang ia cari. Ternyata Ni Umbara sedang mencari anak-anak, karena waktu sudah menunjukkan sore menjelang malam. Ni Umbara memanggil anak-anak beberapa kali, mengingatkan agar tidak terlalu lama bermain diluar sehingga lupa waktu. Kali pertama dipanggil, anak-anak belum saja menunjukkan dirinya. Sampai ketiga kalinya Ni Umbara memanggil anak-anak, akhirnya terdengar suara riuh anak-anak dan terlihat anakanak yang meloncat-loncat menghampiri Ni Umbara. Anak-anak membawa barang kesukaannya masing-masing sambil duduk di hadapan $\mathrm{Ni}$ Umbara. Akhirnya anak-anak berhenti bicara, keadaan jadi sunyi. Lalu Ni Umbara menghitung jumlah anak-anak karena merasa ada yang kurang. Tak lama, datanglah seorang anak di depan Ni Umbara sambil membawa banyak barang hampir menutupi tubuhnya sendiri. Masing-masing anak menceritakan pengalaman bermainnya tadi. Setelah menceritakan pengalamannya, ketujuh anak tersebut masing-masing mendapat nasihat yang berbeda dari Ki Umbara dan Ni Umbara.

Tak lama kemudian, datanglah Princes ke saung. Princes bertanya kenapa Ki Umbara sampai duluan. Namun akhirnya Princes mengakui bahwa di sepanjang perjalanan, ia beberapa kali berhenti untuk mampir dan ia menyesalinya karena datang terlambat. Lalu Princes bersujud karena waktu sudah mendekati Magrib. Tak lama, datang Utun sembari menyahut orang-orang agar tidak terlalu nyenyak dan lupa pada dirinya sendiri. Mengikuti Princes, Utun lalu bersujud. Amar datang sambil membawa barangbarangnya seperti biasa lalu mengobrol sekilas untuk menceritakan bahwa tambangnya masih terbelit. Ki Umbara mengingatkan Amar bahwa kini bukan waktunya untuk membenarkan tambang. Karena itulah, Amar langsung bersujud.

$\mathrm{Ni}$ Umbara heran karena melihat orangorang bersujud di hadapan saung yang akhirnya hanya dibiarkan. Ki Umbara lalu menyuruh $\mathrm{Ni}$ Umbara untuk memanggil anak-anak lagi. Tibatiba, terdengar suara-suara aneh dikuti dengan suara angin bergemuruh dan cahaya-cahaya menyilaukan. Beberapa cahaya yang terkena tubuh Utun, Amar dan Princes dan mereka menghilang seolah terbawa cahaya yang masuk ke saung. Nini dan Aki Umbara berdiri sambil saling 
bergandengan tangan tak lupa memanggil orangorang. Lama kelamaan suara Nini dan Aki Umbara terdengar ketir. Keadaan jadi sunyi. Ni Umbara dan Ki Umbara duduk sambil saling merangkul, tak lupa tangannya tidak lepas dari cempor. Lalu datanglah Budak Angon sambil membawa pecut di tangan kirinya dan cempor besar di tangan kanannya. Budak Angon datang untuk menjemput $\mathrm{Ki}$ Umbara dan Ni Umbara pulang ke gawir magrib. Sambil berjalan digiringkan Budak Angon, Ni Umbara tak lupa untuk memanggil orang-orang agar tak terlalu lama hidup di pengembaraan. Terdengar suara Adzan, diikuti suara tahlil.

\section{Struktur dan Unsur Cerita Naskah Drama "Wanci"}

Teori struktur naskah drama dalam naskah drama "Wanci" menggunakan teori Sumardjo dan Saini dalam Isnendes (2016: 34-35), yang mencakup prolog, dialog, babak, adegan, wawacang, solilokui, aside dan epilog. Prolog atau keterangan dalam pembuka naskah drama yang berfungsi menunjukkan keadaan pertama dalam naskah drama ini bisa atawa katerangan dina bubuka naskah drama nu pungsina nuduhkeun kaayaan mimiti dina ieu naskah drama ada di adegan pertama. Naskah drama ini menggambarkan keadaan pertama secara jelas. Naskah drama ini dibentuk oleh 203 dialog atau percakapan termasuk solilokuinya. Dialog yang dominan diperankan oleh tokoh utama yaitu $\mathrm{Ki}$ Umbara. Naskah drama "Wanci" termasuk drama satu babak. Dalam naskah drama ini ditemukan beberapa wawacang atau kramagung di setiap adegannya. Wawacang atau kramagung yaitu petunjuk untuk aktor yang memudahkan aktor dalam memeragakan perannya. Berdasarkan hasil identifikasi, naskah drama ini memiliki 29 wawacang yang terbagi atas 5 wawacang perasaan dan 24 wawacang perintah. Solilokui yaitu tokoh dalam keadaan sendiri untuk mengungkapkan isi pikirannya atau bisa disebut juga monoloh. Solilokui yang ada dalam naskah drama ini ada 3 , masing-masing terdapat 1 solilokui di setiap adegan. Adegan atau scene ditandai dengan datangnya tokoh baru atau adanya situasi yang berubah. Naskah drama "Wanci" dibentuk oleh 3 adegan. Aside adalah cara tokoh berdialog dengan penonton dan tokoh lainberpura-pura tidak mendengarkan apa yang diceritakannya. Ditemukan adanya aside dalam adegan kedua. Epilog yaitu penutup yang ada di akhir cerita. Setelah diteliti, naskah drama ini diakhiri dengan adanya suara adzan dan suara tahlil setelah $\mathrm{Ki}$
Umbara dan Ni Umbara dalam perjalanan menuju gawir magrib sambil diantar oleh Budak Angon.

Penelitian ini menggunakan teori Hasanuddin untuk menemukan unsur-pembangun cerita yang mencakup 1) tema; 2) tokoh; 3) latar 4) alur; dan 5) amanat. Tema naskah drama "Wanci" karya Ayi G. Sasmita lebih berpusat pada persoalan religi yang ada berupa ungkapaungkapan dari para tokoh. Naskah drama ini juga banyak menggunakan istilah-istilah keagamaan yang biasanya digunakan oleh umat Islam, contohnya seperti "adzan" dan "tahlil". Selain itu, ada juga adegan ketika Ki Umbara mengajarkan bahwa manusia diberi 3 macam nafsu yaitu, nafsu amarah, nafsu lawamah dan nafsu mutmainnah. Ketiga nafsu yang disebutkan merupakan istilah yang digunakan umat Islam. Kesimpulannya, naskah drama ini mempunyai tema religi juga mengandung unsur moral.

Tokoh dalam naskah drama "Wanci" terbagi dua menjadi tokoh utama dan tokoh tambahan. Tokoh utama bias terlihat dari adanya peran mulai dari cerita awal hingga akhir. Bisa disimpulkan bahwa tokoh utama dari naskah drama ini adalah Ki Umbara yang memiliki peran dari awal cerita hingga akhir. Ni Umbara juga bisa disebut tokoh yang memiliki peran penting. Namun jika dibandingkan dengan tokoh Ki Umbara, tentu $\mathrm{Ki}$ Umbara lebih mempunyai peran yang lengkap. Karena itulah, Ni Umbara termasuk tokoh tambahan dibarengi oleh tokoh lainnya yaitu Utun, Amar, Princes, Budak Angon, Harak, Baran, Aura, Giba, Mutma, Kani jeung Jail. Ada total 13 tokoh di dalam naskah drama ini.

Latar mencakup latar tempat, latar waktu dan latar suasana. Latar tempat dalam naskah drama "Wanci" karya Ayi G. Sasmita yaitu tempat aneh tak berpenghuni dan tempat sekitaran saung. Adapun latar gawir magrib yang diceritakan. Namun latar tempat gawir magrib diceritakan hanya menjadi tujuan akhir semua tokoh dan tidak nampak adanya tokoh yang berada di gawir magrib. Latar waktu dalam naskah drama ini ada "wanci haneut moyan", "wanci lingsir ngulon" dan "wanci sareupna". "Wanci haneut moyan" artinya waktu dimana matahari baru terbit dan cuaca mulai hangat. Latar waktu tersebut ada pada adegan kedua saat Utun baru datang ke tempat aneh tak berpenghuni. "Wanci lingsir ngulon" artinya saat matahari mulai bergerak menuju barat. Sedangkan "wanci sareupna" yang berarti matahari sudah terbenam ada dalam adegan ketiga saat Ni Umbara menunggu anak-anak pulang ke saung. Latar suasana dalam naskah drama ini yaitu ada suasana ketir dan suasana lucu atau 
banyol. Namun suasana yang lebih dominan adalah suasana ketir.

Alur yaitu urutan kejadian dalam satu cerita. Berdasarkan hasil penelitian, naskah drama ini mempunyai alur yang konvensional atau maju karena setiap adegan mempunyai hubungan juga diceritakan secara berurutan.

Amanat atau pesan yang ingin disampaikan oleh pengarang melalui naskah drama ini yitu manusia harus saling mengingatkan, jangan lupa untuk melakukan tugas sebagai manusia yang sebenarnya yaitu untuk beribadah kepada Tuhan. Melakukan kebaikan kepada sesama manusia serta memasrahkan segalanya kepada Yang Maha Kuasa sambil terus berikhtiar.

\section{Unsur Semiotik}

Penelitian ini menggunakan teori semiotik Peirce dalam Sukyadi (2011: 25) yang menyebutkan bahwa tipe-tipe seperti ikon, indéks, jeung simbol berdasarkan keberlangsungan fungsi selaku tanda.

Setelah diidentifikasi, naskah drama ini mempunyai 11 ikon yang merupakan tanda yang bisa dikaitkan dengan objeknya serta menandakan adanya hubungan antara penanda dan petandanya. Ikon yang ditemukan mencakup ikon sebutan atau panggilan kepada tokoh contohnya

Utun : Duh meni reuwas. Sabar mang sabar! (hlm. 5)

Kata mang merupakan ikon dari laki-laki yang lebih tua yang menunjukkan bahwa sebutan tersebut ditujukan kepada tokoh Amar. Selain itu, ada juga kalimat

Amar : Oh, aing Amar. Rék kamana manéh jang? (hlm. 5)

Kata jang merupakan ikon dari anak laki-laki yang lebih muda yang ditujukan pada tokoh Utun. Adapun ikon yang menunjukkan sebutan sayang kepada anak contohnya pada kalimat

Ni Umbara : utun inji geura baralik geus sareupna. (hlm. 15)

Kata utun inji merupakan ikon dari jabang bayi atau menandakan kasih sayang ketika $\mathrm{Ni}$ Umbara memanggil anak-anak untuk segera pulang ke saung.

Indeks merupakan tanda yang berpusat pada hubungan kausalitas dan adanya hubungan sebab akibat. Dalam naskah drama ini terdapat 31 indeks. Setelah diidentifikasi, indeks yang ditemukan menunjukkan keadaan rasa dan tingkah laku tokoh contohnya pada kalimat

Ni Umbara : Haneuteun deui Aki saung réyod téh (hlm. 19)

Kata haneuteun merupakan indeks dari rasa bahagia Ni Umbara setelah anak-anak pulang ke saung. Indeks rasa bahagia ini juga ada pada kalimat

Ni Umbara : Wilujeng angkat mugia salamet kanu di tuju. (hlm. 13)

Kata wilujeng merupakan indeks rasa bahagia Ni Umbara yang berpamitan dengan Utun. Indeks rasa khawatir

Ki Umbara : dibandungan titadi jiga nu guligah manah. (hlm. 14)

Kata guligah manah merupakan indeks dari rasa khawatir Ni Umbara karena anak-anak belum pulang ke saung. Indeks amarah tokoh ada pada kalimat

Princés : sangeunahna manéh nyebut ungkluk lacur ka aing! (hlm. 9)

Menunjukkan ekspresi kemarahan tokoh Princes karena tokoh Princes tidak terima disebut pelacur. Selain itu, ada juga indeks yang menunjukkan perasaan tokoh, ada juga indeks keaadaan tokoh seperti

Utun (datang bari rungah-ringeuh).

Kata rungah-ringeuh yang artinya terengahengah merupakan indeks dari keadaan tokoh Utun yang setelah melakukan perjalanan panjang hingga sampai di tempat aneh tak berpenghuni. Kalimat di bawah

Utun : Ah mending reureuh heula di dieu (hlm. 4)

Menunjukkan adanya indeks keadaan tokoh Utun yang merasa capek karena setelah melakukan perjalanan panjang.

Simbol yaitu tanda yang mengubungkan antara tanda dan denotatumnya yang disepakati. Ditemukan ada 37 simbol dalam naskah drama ini. Kebanyakan simbol dalam naskah drama ini berupa istilah. Contohnya seperti pada kalimat 
Amar : Rugi déwék!!! Ngeunah éhé teu ngeunah éon! (hlm. 7)

Yang merupakan simbol yang berarti menang sendiri. Selain itu ada juga simbol pada kalimat

Amar : Éta deuih kawas nu éblég tengah poé mentrang-mentring mamawa cempor. (hlm. 10)

Kata mentrang-mentring merupakan simbol dari panas terik matahari pada tengah hari. Simbol pada kalimat

Amar :Dasar aki nini tujuh mulud (hlm. 10)

Merupakan simbol dari orang tua yang memiliki sifat seperti anak-anak. Adapun simbol dalam kalimat

Amar : Teu gableg cedo (hlm. 10)

Yang artinya tidak punya akal sehat. Simbol yang terdapat pada kalimat

Amar : teu ngukur ka kujur (hlm. 10)

Menandakan adanya simbol yang berarti tidak ingat pada umur. Banyak simbol keagamaan yang digunakan pada naskah drama ini contohnya seperti kata adzan, komat, tahlil, mutmainnah, hijrah, dan mubadzir. Kata alam pangumbaraan dan alam kalanggengan banyak ditulis dalam naskah drama. Alam pangumbaraan yang artinya alam dunia dan alam kalanggengan yang artinya akhirat. Selain itu, pada adegan ketiga penulis menuliskan akhirat dengan istilah nagari tunjung sampurna dan lembur singkur banjar pamidangan sedangkan dalam adegan pertama pengarang menuliskan alam dunia dengan istilah marcapada.

\section{Naskah Drama "Wanci" sebagai Bahan Pembelajaran}

Penelitian ini menggunakan teori kriteria bahan ajar Nasution. Menurut Nasution dalam Haerudin dan Kardana (2013, hlm. 77) yang menyebutkan bahwa kriteria bahan ajar ada 5 yaitu 1) tujuan yang ingin dicapai; 2) dianggap memiliki nilai untuk kehidupan manusia; 3) dianggap memiliki nilai warisan dari jaman sebelumnya; 4) memiliki guna untuk menguasai ilmu lain; dan 5) sesuai dengan kebutuhan dan minat siswa.

Tujuan yang ingin dicapai berkaitan dengan keterampilan berbahasa siswa dalam memahami isi cerita naskah drama. Diharapkan siswa dapat memahami nilai moral dalam naskah drama yang bermanfaat serta siswa bisa membedakan antara hal yang baik dan buruk. Selain itu, ada juga tujuan untuk meningkatkan kemampuan lisan siswa dalam meggunakan bahasa Sunda. Contohnya kemampuan siswa berdialog menggunakan nada dan undak usuk basa yang baik dan benar. Berdasar hasil penelitian, naskah drama "Wanci" karya Ayi G. Sasmita memenuhi syarat di atas.

Dari hasil kajian, naskah drama "Wanci" memiliki nilai kehidupan yang menggambarkan perjalanan manusia. Nilai moral yang ada dalam naskah drama ini digambarkan secara langsung, oleh sebab itu siswa bisa secara langsung pula memahami amanatnya. Selain itu, naskah drama ini bisa membangun karakter siswa melalui penggambaran karakter tokoh, tatakeama bahasa, dan tingkah lakunya. Dengan demikian naskah drama ini jika diapresiasikan secara benar kepada siswa, dapat menuntun kepada perilaku yang baik atau menurut Suherman (2018) dapat turut membentuk kepribadian siswa mendekati kesempurnaan, yaitu yang seimbang antara lahir dan batinnya serta meneladani aspek-aspek kebaikan.

Naskah drama "Wanci" karya Ayi G. Sasmita mempunyai nilai berupa warisan dari jaman sebelumnya berupa tatakrama bahasa dan tingkah laku. Selain itu, naskah drama ini juga banyak menggunakan istilah yang tidak lazim digunakan sehari-hari di jaman. Karena itulah, naskah drama ini bisa membantu meningkatkan kemampuan bahasa dan memperkaya kosa kata siswa.

Berdasarkan hasil penelitian, naskah drama ini mempunyai manfaat untuk menambah wawasan ilmu lainnya seperti dalam bidang kesusastraan, bidang drama, bidang keagamaan, bahkan secara lebih luas bisa menelusuri sebagian dari unsur-unsur budaya yang terkandung dalam karya seni seperti diungkapkan Dwiyanti (2019). Selain banyak menggunakan istilah yang berkaitan dengan kesusastraan, naskah drama ini juga banyak menggunakan istilah yang berkaitan dengan ilmu agama khususnya agama Islam.

Naskah drama ini sesuai dengan kebutuhan siswa dalam pengajaran materi drama yang isinya mencakup analisis naskah drama yang dianggap merupakan kegiatan apresiasi. Selain itu, naskah drama ini dianggap bisa menarik minat siswa karena naskah drama ini mengenalkan aliran drama yang berbeda. 


\section{KESIMPULAN}

Setelah diidentifikasi, naskah drama ini mempunyai struktrur yang lengkap, terdiri atas prolog, dialog, episode, adegan, wawacang, solilokui, aside dan epilog. Tema naskah drama ini yaitu tentang keagamaan (religi). Adapun tokoh dalam naskah drama ini ada 13 yang mencakup tokoh utama dan tambahan. Setiap nama tokoh menggambarkan sipat tokoh itu sendiri. Latar dibagi menjadi tiga jenis yaitu latar tempat, latar waktu dan latar suasana. Latar tempat ada dua yaitu tempat aneh tak berpenghuni dan saung. Latar waktu ada 3 yaitu wanci haneut moyan, wanci lingsir ngulon dan wanci sareupna. Naskah drama ini mempunyai alur maju karena setiap alur yang membangun cerita dalam setiap adegan diceritakan secara runtut. Adapun amanat yang ingin disampaikan pengarang yaitu, sebagai manusai jangan lupa untuk saling mengingatkan, jangan melupakan urusan akhirat karena segala yang dimiliki manusia di dunia hanya sementara dan sekedar titipan.

Berdasarkan hasil analisis, naskah drama "Wanci" karya Ayi G. Sasmita memiliki pengungkapan yang mengandung makna dalam setiap adegannya. Hal tersebut dapat dinilai dari adanya 11 ikon, 31 indeks dan 37 simbol. Ikon menunjukkan adanya kaitan antara petanda dan penanda. Indeks menunjukkan adanya kaitan antara sebab dan akibat. Sedangkan simbol menunjukkan adanya istilah yang biasa digunakan masyarakat umum.

Berkaitan dengan bahan pengajaran, naskah drama "Wanci" memenuhi kriteria bahan pengajaran seperti disyaratkan Haerudin (2019). Naskah drama ini menceritakan tentang perjalanan hidup manusia selama di dunia, mengandung nilai moral dan religi, serta dianggap memiliki manfaat serta dapat membangun karakter. Oleh karena itu, naskah drama ini bisa digunakan sebagai alternatif bahan pengajaran apresiasi drama di SMA kelas XII.

\section{REFERENSI}

Arikunto, S. (2013). Prosedur Penelitian: Suatu Objek Praktik. Jakarta: Rineka Cipta.

Asmaniah, Zainah. (2015). Naskah Drama Rajapati Karangan Ahmad Bakri (Kajian Struktural Pragmastilistik). Jurnal: Lokabasa, Vol. 6, No. 2, Oktober 2015, hlm. 219-226. https://ejournal.upi.edu/

Darisman, Y. (2015). Analisis Naskah Drama Sadrah Karya Nazarudin Azhar (Tilikan Sémiotik). Bandung: Skripsi UPI Bandung.
Dewojati, C. (2010). Drama: Sejarah, Teori dan Penerapannya.Yogyakarta: Gadjah Mada University Press.

Dwijayanto, Andy. (2015). Simbol Teatrikal Pada Naskah Drama "Maaf, Maaf, Maaf: Politik Cinta Dasamuka" Karangan N. Riantiarno: Suatu Kajian Semiotika. Jurnal: Arkhais, Vol 6, No. 1, Juni 2015, Hlm. 1-5. http://journal.unj.ac.id/unj/index.php/arkhais /article/view/365.

Dwiyanti, R., \& Suherman, A. (2019). Unsur Budaya Dalam Cerita Film Cakra Buana Karya Sutradara Massimo Burhanuddin. LOKABASA, 10(2), 204-213.

Endraswara, S. (2011). Metode Pembelajaran Drama (Apresiasi, Ekspresi dan Pengkajian). Jakarta: CAPS.

Faruk. (2015). Metode Penelitian Sastra. Yogyakarta: Pustaka Pelajar.

Haerudin, D, Kosim Kardana. (2013). Panganteur Talaah Buku Ajar. Bandung: DPBS UPI.

Haerudin, D., Suherman, A., \& Nugraha, H. S. (2019, March). The Quality and Values of Character Education in Sundanese Language Text Book of the 2013 Elementary School Curriculum. In Second Conference on Language, Literature, Education, and Culture (ICOLLITE 2018). Atlantis Press.

Hasanuddin, W.S. (1996). Drama: Karya Dalam Dua Dimensi. Bandung: Angkasa.

Isnendes, R. (2010). Kajian Sastra. Bandung: Daluang.

Isnendes, R. (2010). Teori Sastra. Bandung: Jurusan Pendidikan Bahasa Daerah.

Koswara, D. (2010). Sastra Sunda Modern. Bandung: Jurusan Pendidikan Bahasa Daerah UPI.

Mustaqim, Farhan, spk. (2019). Naskah Drama "Hutbah Munggaran di Pajajaran" Karya Yus Rusyana (Kajian Struktural dan Semiotik). Jurnal: Lokabasa, Vol. 10, No. 2, Oktober 2019, Hlm. 124-130. https://ejournal.upi.edu/

Pratama, Tyas Agung. (2018). Naskah Drama Muntangan Alif Karya R. Hidayat Suryalaga untuk Bahan Pembelajaran Membaca Dramadi SMP/MTS (Kajian Struktural dan Semiotik). Jurnal: Lokabasa, Vol. 9, No. 1, April 2018, Hlm. 95-106. https://ejournal.upi.edu/

Semi, A. (2012). Metode Penelitian Sastra. Bandung: Angkasa.

Stanton, R. (2012). Teori Fiksi: Robert Stanton. Yogyakarta: Pustaka Pelajar Offset. 
Suherman, A. (2018). Jabar Masagi: Penguatan Karakter Bagi Generasi Milenial Berbasis Kearifan Lokal. Lokabasa, 9(2), 107.

Suherman, A. (2019). Literacy Tradition of Sundanese Society-Indonesia. International Journal for Innovation Education and Research, 7(3), 262-271. https://doi.org/10.31686/ijier.Vol7.Iss3.1377 